\title{
VIVÊNCIAS EM PROMOÇÃO DA SAÚDE: ARTICULANDO SABERES COM ESTUDANTES DE ESCOLAS PÚBLICAS
}

\author{
Priscila Milano Corrêa \\ Universidade Federal do Rio Grande \\ priscila.milano@yahoo.com.br \\ Stela Henkes \\ Universidade Federal do Rio Grande \\ stela.henkes@yahoo.com.br \\ Renan Lanau \\ Universidade Federal do Rio Grande \\ renanlanau@hotmail.com \\ Camila Marins Dutra \\ Universidade Federal do Rio Grande \\ camilamarinsdutra@yahoo.com.br
}

\author{
Cristina Dutra Ribeiro \\ Universidade Federal do Rio Grande \\ crisdribeiro@yahoo.com.br \\ Ozeia Simões Franco \\ Universidade Federal do Rio Grande \\ professorozei@hotmail.com \\ Maitê Peres de Carvalho \\ Universidade Federal do Rio Grande \\ maite_carvalho@yahoo.com.br \\ Maria Cristina Flores Soares \\ Universidade Federal do Rio Grande \\ mcflores01@gmail.com
}

\section{Resumo}

A escola constitui-se em uma instituição com princípios educacionais que deve contribuir na formação dos sujeitos, bem como na construção de valores pessoais significativos à conduta humana, sendo também um espaço para a vivência em saúde. Neste estudo apresentamos um relato de experiência que aborda as atividades do "Programa Vivências em Promoção da Saúde na Escola", desenvolvido em 2012, com estudantes de séries iniciais do ensino fundamental de duas escolas públicas do município do Rio Grande/RS no que se referem a questões da promoção da cidadania e cultura da paz. Os resultados demonstram que a interação dos estudantes com a atividade e com os colegas é imprescindível e necessária ao fazer pedagógico e à promoção em saúde.

Palavras-chave: Promoção da Saúde. Estudantes. Cultura. Ensino. Direitos Humanos.

\section{EXPERIENCES IN HEALTH PROMOTION: ARTICULATING KNOWLEDGE WITH PUBLIC SCHOOL STUDENTS}

\begin{abstract}
The school is an institution with educational principles that should contribute to the formation of subjects, as too in building personal values to human conduct, being also a space for experiences in health. This study presents an experience report that discusses the activities of the "Experiences Program in Health Promotion in the School", developed in 2012, with students in the early grades of elementary school of two public schools in the city of Rio Grande/RS concerning the questions of promoting citizenship and culture of peace. The results show that the interaction of students with the activity and with colleagues is essential and necessary to make teaching and to health promotion.

Keywords: Health Promotion. Students. Culture. Teaching. Human Rights.

\section{EXPERIENCIAS EN PROMOCIÓN DE LA SALUD: CONOCIMIENTO ARTICULADO COM ESTUDIANTES DE ESCUELAS PÚBLICAS}

\section{Resumen}

La escuela es una instituición con los principios educativos que deben contribuir a la formación de las personas, así como en la construción de valores personales importantes para la conducta humana, y es también un espacio para la experiencia en salud. En este estudio se presenta un relato de experiencia que se ocupa de las actividades del "Programa Experiencias en Promoción de la Salud en la Escuela", desarrollado en 2012, com estudiantes en los primeros grados de la escuela primaria pública de la ciudad de Río Grande/RS al referirse a las questiones de la promoción de la ciudadanía y la cultura de paz. Los resultados muestran que la interación de los estudiantes con la actividad y con los colegas es essencial y necesaria para la promoción de la ensañanza y de la salud.

Palabras clave: Promoción de la Salud. Estudiantes. Cultura. Enseñanza. Derechos Humanos. 
VIVÊNCIAS EM PROMOÇÃO DA SAÚDE: ARTICULANDO SABERES COM ESTUDANTES DE ESCOLAS PÚBLICAS

\section{INTRODUÇÃO}

O espaço pedagógico é um ambiente solidário a estímulos da vida saudável e de qualidade de vida. Dessa forma, deve estar engajado no desenvolvimento de políticas públicas saudáveis e de entornos favoráveis à saúde, bem como à aprendizagem que permita a proteção do meio ambiente, a conservação de recursos naturais e do patrimônio público. Além disso, Aerts et al. (2004) salienta que deve haver o estímulo de comportamentos como o respeito aos colegas, aos professores e à diversidade; a prática de valores como a solidariedade e a tolerância; hábitos de alimentação saudável, de atividades físicas e de boa postura e, ainda, a prevenção de acidentes. Todos esses fatores são inerentes à promoção da saúde e permeiam a vivência escolar.

A expressão "saúde na escola", conforme aponta Valadão (2004), é utilizada para designar um campo que compreende concepções, diretrizes, programas, projetos e ações voltadas à saúde que ocorrem no cenário da escola, sejam de natureza educativa, preventiva ou assistencial. Nesse sentido, a "promoção em saúde na escola" corresponde a uma visão e a um conjunto de estratégias que têm como objetivo produzir repercussões positivas sobre a qualidade de vida e os determinantes de saúde dos membros da comunidade escolar.

Para promover saúde, com base nos princípios de Ottawa (1986), não é suficiente apenas informar. É necessária uma relação dialógica, através da comunicação emancipadora, onde os sujeitos sejam envolvidos na ação educativa, formativa, construtiva e criativa, levando em consideração a reconstrução do saber e do fazer. Promover saúde implica e requer que se tenha educação, alimentação, renda, ecossistema saudável, recursos sustentáveis, justiça, paz e equidade, além de desenvolver ações de promoção em saúde. No contexto escolar, deve-se relacionar com respeito às possibilidades e aos limites do corpo, do intelecto e das emoções, da participação social e do estabelecimento de alianças (AS CARTAS DE PROMOÇÃO DA SAÚDE, 2002).

A promoção em saúde tem como objetivos modificar a visão assistencialista da saúde por meio da formulação e implementação de políticas saudáveis, movimentos organizados e iniciativas em programas nos diversos setores da sociedade, conforme os pressupostos estabelecios na carta de Ottawa (1986) que compreende a promoção em saúde como "o processo de capacitação de vida e saúde, incluindo uma maior participação no controle do processo". O mesmo documento ainda afirma que a saúde é um conceito positivo - que enfatiza recursos sociais, pessoais e capacidades físicas - recursos inerentes ao desenvolvimento social, econômico e pessoal, assim como uma importante dimensão para a qualidade de vida (AS CARTAS DE PROMOÇÃO DA SAÚDE, 2002). 
VIVÊNCIAS EM PROMOÇÃO DA SAÚDE: ARTICULANDO SABERES COM ESTUDANTES DE ESCOLAS PÚBLICAS

A Secretaria de Políticas da Saúde, do Ministério da Saúde (2002), em seu documento “A promoção da saúde no contexto escolar" relata que saúde é um dos temas transversais apontados pelos Parâmetros Curriculares Nacionais que envolvem desde a pluralidade cultural, a ética, a orientação sexual, a cidadania, o meio ambiente e até mesmo o trabalho e o consumo, que lidam com as condições concretas de sujeitos e comunidades sendo complementares e interdependentes. No cotidiano escolar, esses temas emergem em situações concretas de violência, de preconceito, nas tomadas de decisões, nas interações e na organização dos rituais e das festas, nos impasses entre pessoas e grupos, nos conteúdos dos textos e materiais de estudo e de trabalho.

Nessa perspectiva, Michaud (2003) destaca a importância dos profissionais envolvidos na proposta de um programa que requer conexão e interação no meio escolar. Tais profissionais necessitam estar munidos de conhecimento a respeito da melhor logística, e de percepção ao entorno de peculiaridades daquela comunidade para que realmente se obtenha sucesso neste tipo de iniciativa. Saber cativar e oferecer justamente os subsídios mais carentes naquela população é o ponto-chave. Quando se abordam temáticas voltadas à escola, primeiramente, sempre vem à mente a criança e o adolescente, porém, para que um programa seja bem sucedido é necessário o comprometimento de alguns coadjuvantes nesse processo, como, por exemplo, a família e os professores (DESSEN e POLONIA, 2007).

De acordo com Eckermann et al. (2014), programas de promoção da saúde e prevenção de doenças necessitam de algumas estratégias para obter sucesso e adesão da comunidade. Principalmente quando a abordagem desses programas é voltada às crianças e aos adolescentes em fase escolar, o comprometimento e a integração da família tornam-se imprescindíveis. Demonstrar que valoriza o ambiente de estudo dos filhos incentiva e aproxima o relacionamento familiar. Ademais, dinâmicas extracurriculares que façam a criança descobrir coisas novas de uma forma diferenciada, oportuniza o aprendizado com muito mais qualidade e, quando há interação da família, esse aprendizado extrapola as barreiras da escola e da casa para ser propagado pela comunidade em geral.

Heer (2011) ainda reforça que a grande vantagem dos programas de promoção da saúde é a abrangência que podem assumir. Muitas vezes, o programa tem uma população-alvo específica, mas, se bem elaborado, pode atingir proporções ainda maiores com efetividade. Porém, esses resultados exigem profissionalismo na logística e comprometimento das partes para que seja possível perpetuar bons frutos no futuro.

Baseado nesses preceitos é proposto o "Programa Vivências em Promoção da Saúde na Escola". Neste relato de experiência apresentaremos atividades referentes ao projeto "Sou 
VIVÊNCIAS EM PROMOÇÃO DA SAÚDE: ARTICULANDO SABERES COM ESTUDANTES DE ESCOLAS PÚBLICAS

criança, mas já sou cidadão!”, o qual propõe o estímulo e o exercício da cidadania e da cultura da paz entre os estudantes e a comunidade escolar.

\section{MATERIAL E MÉTODOS}

O "Programa Vivências em Promoção da Saúde na Escola" é um projeto de extensão interdisciplinar, realizado no município do Rio Grande/RS. Compreende cinco projetos que abordam os temas de: alimentação saudável (“O que tem de 'bom' para comer hoje?”), cidadania e cultura da paz (“Sou criança, mas já sou cidadão!”), prevenção de acidentes (“'Onde mora o perigo?”), ambiente (“Eu cuido do ambiente e o ambiente cuida de mim!”), atividade física e postura (“Fazendo as pazes com o meu corpo: ele merece!”). Esse programa oportuniza a alunos, educadores e pais algumas práticas, reflexões e vivências em promoção da saúde, por meio da cooperação e articulação político-social entre universidade e comunidade.

Participaram deste programa efetivamente 500 estudantes de cinco escolas municipais de ensino fundamental do município do Rio Grande/RS, com os quais foram utilizadas diversas dinâmicas de grupo, dentre elas "Depedência mútua" e "Escolhendo nossos políticos".

As dinâmicas ocorreram de março a agosto de 2012 e foram desenvolvidas por quatro acadêmicos de cursos distintos de graduação (educação física, direito, enfermagem e letras) da Universidade Federal do Rio Grande (FURG) sendo supervisionados por dois facilitadores pósgraduandos (fisioterapeuta, educador físico) da mesma instituição e a coordenadora deste projeto (fisioterapeuta). O tempo de desenvolvimento das atividades em cada escola foi de 30 dias. As intervenções foram realizadas em todas as turmas do ensino fundamental das cinco escolas. Sendo que para trabalhar o mesmo tema (cidadania e política), utilizamos atividades distintas para escolares do $2^{\circ}$ ao $4^{\circ}$ ano, e do $5^{\circ}$ ao $8^{\circ}$ ano.

Ao iniciar as atividades nas escolas foi realizada uma investigação a respeito do conhecimento prévio dos escolares sobre os temas propostos pelo projeto (alimentação saudável, cidadania e cultura da paz, prevenção de acidentes e ambiente em que vivemos, além de atividade física e saúde). Pois, antes de orientar as ações de saúde é necessário conhecer os indivíduos para os quais se destinam essas práticas. Também é preciso envolvê-los efetivamente nessas ações, de modo a não criar nenhum tipo de imposição, pois pela participação comunitária é possível assegurar sustentabilidade e efetividade das ações de saúde (ALVES, 2005).

A partir desse diagnóstico inicial as ações foram desenvolvidas em uma concepção dialógica em que as vivências dos participantes alimentaram o binômio ação-reflexão e 
VIVÊNCIAS EM PROMOÇÃO DA SAÚDE: ARTICULANDO SABERES COM ESTUDANTES DE ESCOLAS PÚBLICAS

esperando-se que como resultados dessa reflexão fossem adotadas novas práticas de promoção da saúde (RUIZ-MORENO et al., 2005).

Como forma de avaliação do programa foram realizados encontros semanais de cada grupo com seu facilitador e professor coordenador. Ao final da estada em cada escola era realizada uma reunião com todos os componentes do programa para discussão das atividades desenvolvidas, apresentação de sugestões e averiguação do atendimento das metas. Ainda com o objetivo de avaliação, ao longo de todo o ano foram realizados encontros com a direção e professores das escolas para que fosse possível averiguar a abrangência das atividades propostas pelo programa. Na sequência, descreveremos especificamente duas atividades desenvolvidas.

\section{Dependência Mútua}

Neste exercício, começa-se dividindo a turma em duplas. Após serem definidas, um aluno por vez deve ter seus olhos vendados, o qual caminhará - guiado apenas por seu colega da dupla de uma das extremidades do pátio até a outra (aproximadamente dois minutos); sendo que os educandos devem sair de uma das extremidades do pátio e chegar até a outra ponta. Nesta dinâmica não é permitido abrir os olhos nem tocar no colega da dupla, como também em nenhum outro colega do grupo, somente os comandos de voz do colega o auxiliará a chegar ao final. O colega, não vendado, apenas auxiliará o outro dizendo "para frente", "para trás", “cuidado, obstáculo à frente”, “à direita”, “à esquerda", "atenção, não toque no colega", "parabéns, conseguimos chegar até o nosso destino". Logo em seguida, troca-se o papel entre os participantes para que todos tenham a experiência de ambas funções (FRIEDMANN, 2001; VYGOTSKY, 1984; GARCIA, 2006).

Depois de todas essas etapas concluídas, deve-se reunir todos os educandos afim de que se possa compartilhar as sensações e os sentimentos vivenciados com a dinâmica. Neste momento, alguns questionamentos devem ser dispostos aos alunos: "O que você sentiu quando estava sendo guiado pelo colega?", "Em algum momento da atividade sentiu vontade de abrir os olhos?", "Teve total confiança em seu colega?", "Pensou em se 'vingar' do colega quando chegou a sua vez de ser o guia?", "Sentiu-se tentado a fazer alguma 'brincadeira' de mau gosto com o colega enquanto ele era o guiado?”. Procura-se ainda discutir com o grupo conceitos de humildade, coleguismo e a forma como se sentem as pessoas que não têm o sentido da visão, já que todos esses sentimentos são possíveis a partir dessa dinâmica.

Posteriormente, ainda questiona-se: "O que acreditas que falta em ti para que as pessoas confiem mais no teu auxílio?", "Qual a maior ajuda que acreditas ter dado ao teu colega nesta atividade?", "Neste momento da tua vida, qual a melhor ajuda que poderias dar para o grupo?". 
VIVÊNCIAS EM PROMOÇÃO DA SAÚDE: ARTICULANDO SABERES COM ESTUDANTES DE ESCOLAS PÚBLICAS

\section{Escolhendo nossos políticos}

Tendo em vista as eleições políticas do ano de 2012 para prefeito e vereadores, propôs-se que escolhessem seus representantes. Inicialmente, dialoga-se com as turmas quais os papéis e as funções de prefeitos e vereadores para uma comunidade. Após esse momento, solicita-se que cada aluno escolha o nome de apenas um colega e o indique ao cargo público.

Dessa forma, os dois estudantes mais votados de cada turma são candidatos a prefeito, os outros dois como candidatos a vice-prefeito e cinco seguintes mais votados são indicados ao cargo de vereador. Explica-se que apenas um candidato é escolhido como prefeito, um como vice-prefeito e dois como vereadores e que, para tanto, realiza-se uma eleição na turma e os referidos indicados serão os candidatos da política. Os alunos que não recebessem votos suficientes à indicação de um desses cargos públicos deveriam ser os cabos eleitorais dos demais colegas.

Explica-se que, em toda a eleição, os candidatos mostram ao público o porquê devem receber seu voto e que isso ocorre por meio de campanhas políticas que incluem propostas de melhorias para a sociedade em diversos setores. Dessa forma, propusemos que também fizessem o mesmo, pois somente assim seus eleitores teriam condições de conhecer os candidatos e saber se é pertinente o voto àquele pretendente a um cargo público (VYGOTSKY, 1984; BIAGGIO, 1997).

\section{RESULTADOS E ANÁLISE}

Neste trabalho, optou-se por trabalhar utilizando brincadeiras, partindo-se do princípio de que é das brincadeiras que as crianças constroem suas experiências e relacionam-se com o mundo de modo ativo, experimentam a tomada de decisões, desenvolvem a autonomia, a criatividade e a responsabilidade por seus próprios atos (QUEIROZ, 2006).

\section{Contextualizando a ação "Dependência Mútua"}

Os objetivos desta atividade foram revelar o quanto são importantes as relações interpessoais, o quanto podemos contribuir para o crescimento de cada colega e o quanto isso contribui para a formação de grupos. Através da privação do sentido da visão propiciou-se também aos participantes ter a experiência de algumas limitações e dificuldades em situações cotidianas vividas por quem possui deficiência visual, articulando-se a essa atividade conceitos de acessibilidade, humildade e cidadania. Esta dinâmica foi vivenciada com 160 estudantes, de idades 
VIVÊNCIAS EM PROMOÇÃO DA SAÚDE: ARTICULANDO SABERES COM ESTUDANTES DE ESCOLAS PÚBLICAS

entre sete e doze anos, das turmas de $2^{\circ}, 3^{\circ}$ e $4^{\circ}$ ano do ensino fundamental, cada turma com 20 a 30 alunos aproximadamente.

Os estudantes mostraram-se muito participativos na dinâmica e, ao relatarem suas sensações, as falas foram quase que unívocas: "A brincadeira é muito boa e eu gostei bastante"; "Gostei bastante da brincadeira, mas me senti um pouco mal, não sabia que era tão ruim ficar sem ver as coisas"; "A sensação de não ver as coisas é muito triste, agora eu sei como um cego se sente"; "Senti uma angústia, minha vontade era de arrancar aquilo dos meus olhos, é muito triste e ruim não ver as coisas, gostei bastante da atividade nunca tinha tido oportunidade antes de saber como é ficar sem ver as coisas, acho que vou dar mais valor à minha visão agora".

Ao fim da atividade explicamos o propósito da dinâmica e discutimos com os estudantes que, sem dúvida alguma, precisamos uns dos outros, precisamos interagir e o quanto podemos contribuir para o crescimento mútuo de modo colaborativo. Compreendemos com isso, que os estudantes tiveram contato com conceitos e aspectos inerentes ao afeto, ao respeito e à solidariedade, bem como a cidadania e cultura de paz, a cooperação e a tolerância ampliando a visão de grupo e comunidade.

Estudo desenvolvido por Dias (2007) objetivou apresentar o Estatuto da Criança e do Adolescente a crianças de 7 a 10 anos, de maneira lúdica, proporcionando aprendizado sobre a legislação, instigando a reflexão, a participação, a inclusão social e o empoderamento, os autores relatam a dificuldade de abordar a legislação se a equipe não utilizar boas estratégias permeadas de ludicidade, e acrescentam que as crianças são ótimas disseminadoras de conhecimentos.

Reis (2000) defende que a educação para a cidadania deve ser colocada na agenda escolar, por ser a escola um local intermediário entre a família e a vida pública em seu aspecto social e político, e ainda que a educação em cidadania deve adequar-se aos desafios educativos de nosso tempo, sendo assim suscetível a interpretações plurais.

\section{Contextualizando a ação "Escolhendo nossos políticos"}

O objetivo desta atividade foi conscientizar os estudantes a respeito da importância e da responsabilidade de escolhermos nossos representantes políticos, pensando e repensando suas propostas apresentadas à população em tempo de eleição.

Esta atividade foi desenvolvida com 340 educandos, de idades entre nove e doze anos, das turmas de $4^{\circ}, 5^{\circ}, 6^{\circ}, 7^{\circ}$ e $8^{\circ}$ ano do ensino fundamental, cada turma com 30 a 38 alunos aproximadamente.

Ao propormos a atividade não tínhamos ideia da proporção que a mesma obteria, visto que, em nenhuma outra dinâmica, a participação foi tão fervorosa quanto nesta. E, não foram 
VIVÊNCIAS EM PROMOÇÃO DA SAÚDE: ARTICULANDO SABERES COM ESTUDANTES DE ESCOLAS PÚBLICAS

apenas os alunos que participaram, os professores e os pais também tiveram seus papéis desempenhados, uma vez que auxiliaram os educandos em suas "campanhas".

A atividade foi dividida em quatro encontros: no primeiro encontro propusemos o exercício e os alunos escolheram os candidatos para indicação aos cargos; no segundo encontro, os candidatos indicados (com o auxílio dos cabos eleitorais) criaram suas campanhas (desde propostas, "santinhos", bandeiras, adesivos, bótons e camisetas de seus candidatos e partidos); no terceiro encontro os candidatos tiveram a oportunidade de mostrar ao público suas propostas, bem como fazer seus "bandeiraços", vestir suas camisetas e bótons, distribuir adesivos e "santinhos" de sua campanha eleitoral e cantar seus jingles ao público e, no último encontro foi o momento destinado à votação, para o qual se confeccionou uma urna de papelão (imitando a urna eletrônica).

Dentre as propostas dos candidatos estavam desde a melhoria da infraestrutura da escola, em especial os banheiros que necessitavam de reformas, a modificação na merenda da escola tornando-a mais saudável e variada com o acréscimo de frutas, iogurtes e barras de cereais no cardápio; atendimentos de saúde, uma vez que nenhum profissional da área está presente neste espaço; mais espaços para lazer; aulas de atividades físicas mais variadas com danças de rua e dança do ventre; criação de espaço para aulas de teatro e música; bem como a construção de um ambiente destinado exclusivamente a atividades físicas e uma pracinha de recreação destinada aos educandos mais jovens.

Essas "propostas" na verdade podem ser traduzidas em reivindicações, uma vez que representam melhorias em diversos aspectos tanto da qualidade de ensino como do lazer, da qualidade de vida e de saúde da coletividade dos educandos, assim questionamos quanto ao direito ao exercício da cidadania por parte das crianças, o direito de participar das decisões que implicam diretamente em suas vidas.

Um estudo realizado com crianças de idades entre nove e onze anos procedentes de escolas particulares urbana, público-urbana e pública-rural constatou que as mesmas têm pouca consciência de seus direitos uma vez que seus conceitos são predominantemente espontâneos (SANTOS, 2007). Tomás (2007) defende uma concepção de cidadania em que crianças e jovens devem ser vistos como atores sociais imprescindíveis e participativos na sociedade, o que implica em direitos e condições ao exercício dessa participação, o que está em acordo com o conceito de cidadão que Santos (1997) propõe, em que cidadão é o indivíduo que tem a capacidade de entender o mundo e a sua situação nele, bem como compreender os seus direitos para poder reivindicá-los. 

ESCOLAS PÚBLICAS

Rezende e Dantas (2009) destacam que a escola tem o compromisso com a formação humana e técnica, transformando concepções e práticas relacionadas à saúde de forma sistemática e institucionalizada por meio de projetos político-pedagógicos contribuindo na interação entre saúde e educação, sendo necessário investir no desenvolvimento de uma comunidade que constrói e se envolve para educar a si mesma, pelos seus cidadãos.

Outro relevante aspecto a destacar neste projeto é a vivência que tiveram os acadêmicos envolvidos, visto que, apesar de suas diferentes áreas acadêmicas, todos exerceram de certo modo, o papel de educadores e receberam de volta um importante e rico aprendizado, pois, segundo Freire (2002, p.25), "quem ensina aprende ao ensinar, e quem aprende ensina ao aprender". Assim, os envolvidos no processo cresceram junto com sua prática e levaram para suas vidas pessoais e profissionais uma experiência privilegiada, um olhar diferente do espaço que, normalmente, deixamos adormecido em nossa memória e voltamos a perceber quando dele passam a fazer parte, os nossos filhos.

\section{CONSIDERAÇÕES FINAIS}

Por meio das atividades realizadas foi possível perceber que é desde a época escolar que as crianças revelam suas demandas e necessidades para o cuidado consigo e com o próximo, o respeito e a reciprocidade. Nesse ínterim, observa-se que é o espaço de encontro entre saúde e educação, uma vez que foi possível diagnosticar que quanto mais consolidações e parcerias se fizerem presentes, mais se observarão práticas de solidariedade e cooperação. A cidadania e cultura de paz são aspectos inerentes não apenas à constituição e o direito à saúde e à educação, mas, além disso, são fatores fundamentais para a implementação de qualquer ação que inclua sujeitos em prol de melhorias, qualidade de vida e bem-estar.

A proximidade com as crianças, numa perspectiva que leva em conta suas vivências, suas realidades e seus diferentes saberes articulados com os saberes adultos, torna a escola uma parceira na construção de ideias e práticas efetivas; ação que não se faz em um espaço restrito, mas que pode ser realizada pela união desses setores, mediados por ações com as famílias, a comunidade e a universidade. As oportunidades foram propostas e nossos anseios e desejos são pela articulação de atividades que propiciem o pensar diante das vivências e da promoção em saúde no âmbito pedagógico.

É necessário estimular o ambiente escolar - enquanto um espaço afetivo de vivência e promoção da saúde - e que os alunos sejam encorajados a assumir seu papel de sujeitos sociais, 

ESCOLAS PÚBLICAS

capacitados a cuidar de si, não apenas do corpo, mas também da mente e do lado afetivo, uma vez que a saúde só se mostra completa a partir da articulação de todos esses preceitos, capacitando-os a cuidar de si por meio de processos educativos estruturados que lhes facilite a adquirir e pôr em prática os conhecimentos, atitudes, habilidades, valores e competências necessárias à promoção e à proteção da própria saúde, de sua família e de sua comunidade.

Em síntese, o desafio de vivenciar e promover saúde na escola consiste em uma política transversal e intersetorial em que dialogam saúde, educação e comunidade, compondo rede de compromissos e responsabilidade quanto à qualidade de vida dos sujeitos, onde todos são atores do cuidado com a saúde.

\section{REFERÊNCIAS}

AERTS, Denise; ALVES, Gehysa Guimarães; LA SALVIA, Maria Walderez; ABEGG, Claídes. Promoção de saúde: a convergência entre as propostas da vigilância da saúde e da escola cidadã. Cad. Saúde Pública, v.20, n.4, p.1020-1028, 2004.

ALVES, Vania Sampaio. Um modelo de educação em saúde para o Programa Saúde da Família: pela integralidade da atenção e reorientação do modelo assistencial. InterfaceComunic, Saúde, Educ, v.9, n.16, p.39-52, 2005.

BIAGGIO, Angela Maria Brasil. Kohlberg e a "Comunidade justa": promovendo o senso ético e a cidadania na escola. Psicologia: reflexão e crítica. Porto Alegre, v.10, n.1 p.47-69, 1997.

BRASIL. MINISTÉRIO DA SAÚDE. AS CARTAS DE PROMOÇÃO DA SAÚDE. CARTA DE OTTAWA. In: Ministério da Saúde (BR). Secretária de Políticas de Saúde. Projeto Promoção da Saúde, 2002.

BRASIL. MINISTÉRIO DA SAÚDE. SECRETARIA DE POLÍTICAS DE SAÚDE. A promoção da saúde no contexto escolar. Rev. Saúde Pública, v.36, n.2, p.533-535, 2002.

DESSEN, Maria Auxiliadora; POLONIA, Ana da Costa. A família e a escola como contextos de desenvolvimento humano. Paidéia, v.17, n.36, p.21-32, 2007.

DIAS, Silvia Luci de Almeida; SIEBEN, Marjorie; COZER, Patrícia; ALVES, Roberta Borghetti; HALBERT, Tiago. Estatuto da Criança e do Adolescente: aprendendo cidadania. Inclusão Social, v. 2, n. 2, 2007.

ECKERMANN, Simon; DAWBER, James; YEATMAN, Heather; QUINSEY, Karen. Evaluating return on investiment in a school based health promotion and prevention program: The investiment multiplier for the Stephanie Alexander Kitchen Garden National Program. Social Science \& Medicine, v.114, p.103-112, 2014. 
VIVÊNCIAS EM PROMOÇÃO DA SAÚDE: ARTICULANDO SABERES COM ESTUDANTES DE ESCOLAS PÚBLICAS

FREIRE, Paulo. Pedagogia da autonomia: saberes necessários à prática educativa. 21.ed. São Paulo: Paz e Terra, 2002, 25p.

FRIEDMANN, Adriana. Brincar, crescer e aprender - O resgate do jogo infantil. São Paulo: Moderna, 2001.

GARCIA, Joe. Indisciplina, incivilidade e cidadania na escola. In: ETD: Educação Temática Digital 8, v.1,p.124-132, 2006.

HEER, Hendrik; KOEHLY, Laura; PEDERSON, Rockie; MORERA, Osvaldo. Effectiveness and Spillover of na After-school Health Promotion Program for Hispanic Elementary School Children. American Journal of Public Health, v.101, n.10, p.1907-1913, 2011.

MICHAUD, Pierre-André. Prevention and Health Promotion in School and Community Settings: A Commentary on the International Perspective. Journal of Adolescent Health, v.33, p.219-225, 2003.

QUEIROZ, Norma Lucia Neris de; MACIEL, Diva Maria Moraes Albuquerque; BRANCO, Angela Uchôa. Brincadeira e desenvolvimento infantil: um olhar sociocultural construtivista. Paidéia, v.16, n.34, p.169-179, 2006.

REIS, João. Cidadania na escola: Desafio e compromisso. Inforgeo, v.15, Lisboa, Edições Colibri, p.105-116, 2000.

REZENDE, Regiane; DANTAS, Vera Lúcia de Azevedo. Apresentação da Série Saúde e Educação: Uma relação possível e necessária. In: Saúde e Educação: Uma relação possível e necessária, ano XIX, boletim 17, 2009. Disponível em: <http://www.tvbrasil.org.br/fotos/salto/series/15061117-SaudeeEdurelacao.pdf> Acesso em: 21 mar. 2015.

RUIZ-MORENO, Lídia; ROMAÑA, Maria Alicia; BATISTA, Sylvia Helena; MARTINS, Maria Aparecida. Jornal Vivo: relato de uma experiência de ensino-aprendizagem na área da saúde. Interface-Comunic, Saúde, Educ, v.9, n.16, p.195-204, 2005.

SANTOS, Gilberto Lima dos; CHAVES, Antonio Marcos. Significados que as crianças atribuem aos seus direitos. Revista brasileira de crescimento e desenvolvimento bumano, v. 17, n. 2, p. 87-97, 2007.

SANTOS, Milton. As Cidadanias Mutiladas. In: Preconceito. São Paulo: Secretaria da Justiça e da Defesa da Cidadania do Estado de São Paulo, 1997.

TOMÁS, Catarina. "Participação não tem Idade” Participação das Crianças e Cidadania da Infância. Revista Contexto \& Educação, v. 22, n. 78, p. 45-68, 2013.

VALADÃO, Marina Marcos. Saúde na Escola: Um campo em busca de espaço na agenda intersetorial. Tese de Doutorado apresentada à Universidade de São Paulo - Faculdade de Saúde Pública, 2004. Disponível em: <http://www.teses.usp.br/teses/disponiveis/6/6135/tde12022007-152151/> Acesso em 15 mar. 2015.

VYGOTSKY, Lev Semenovitch. A formação social da mente. São Paulo: Martins Fontes, 1984. 